\title{
Faces do feminino em histórias de vida: Narrativas e experiências de mulheres brasileiras*
}

\section{Fernando Luiz Cássio**}

Narrativas e experiências: histórias orais de mulheres brasileiras é para ser lido sem pressa. A estrutura é despretensiosamente simples: dez histórias de vida de mulheres brasileiras apresentadas e comentadas por dez historiadoresoralistas fortemente envolvidos com o ofício. O trabalho textual é a marca formal comum - entrevistas transcritas e transformadas em textos de qualidade literária, autobiográficos, confessionais em muito distantes da sisudez não rara nos volumes voltados exclusivamente ao público acadêmico.

O prefácio de Esmeralda Blanco B. de Moura dá o tom da obra: "a circularidade da qual resulta, o entrelaçar de entrevistadores, entrevistadas e entrevistas que não subverte $\mathrm{o}$ singular" (p.7). Idade, local de nascimento, cor da pele, vivências familiares e profissionais - marcas do individual - não isolam estas mulheres do resto do mundo; as insculpem nele. Singularidade sim; excentricidade jamais. Nem heroínas nem vítimas. Mulheres, apenas. Lê-las é deixar-se arrebatar e carregar por suas histórias fluxos vivos, pungentes, generosos - para destinos deliciosa $e$ inevitavelmente desconhecidos.

Podemos começar por Monalisa, garota de programa que ganha a vida no Sul da Flórida. No hotel cinco estrelas onde atendia a seus clientes, entre um e outro programa, cedeu entrevista a Valéria Barbosa de Magalhães. Oportunidades financeiras, desapontamentos profissionais, o afastamento da

\footnotetext{
" Resenha de VÁRIOS AUTORES. Narrativas e Experiências: Histórias orais de mulheres brasileiras. São Paulo, D'Escrever/Letra e Voz, 2009. Recebida para publicação em setembro de 2009, aceita em novembro de 2009.

** Aluno de Doutorado no Instituto de Química da Universidade de São Paulo, com bolsa FAPESP. E-mail: fernando@cecm.usp.br .
} 
família e a estereotipia da mulher brasileira no exterior talham a sua fala corajosa e oferecem outro olhar para a profissão de prostituta - mais que "vida fácil", efeito de uma causa, a imigração para a Flórida e os seus desdobramentos sociais $e$ pessoais. "O dinheiro pesa para eu continuar dançando. É muito dinheiro, ganho mais do que um gerente de banco, só que o gerente vai ter a profissão a vida inteira, eu não".

Noah Osman Turk, entrevistada por Samira Adel Osman, é da primeira geração brasileira da família de imigrantes libaneses. Se Monalisa se afasta dos seus, estes sempre estiveram presentes na história de Noah como guardiões das tradições e protagonistas de confrontos socioculturais inconciliáveis. "Foi na adolescência que eu comecei a sentir o peso dos costumes familiares...". A demarcação dos papéis masculino e feminino - o primeiro provedor e o segundo mantenedor - forja o ambiente infantil de Noah, em muito dependente das relações entre mãe, filha e irmãs. Ao mesmo tempo, a difícil adaptação à vida no Brasil parece reforçar o valor da cultura árabe: Noah mantém os filhos dentro das tradições e planeja viver com o marido no Líbano.

Dona Ana, Ana Luiza da Silva, é devota de Nossa Senhora do Rosário dos Homens Pretos. Quase octogenária, viúva e mãe. Assim o historiador Rodrigo de Almeida Ferreira nos apresenta a sua entrevistada, cuja história é a própria história da Marujada e da Festa do Rosário, festas religiosas das quais participa desde os doze anos. $\mathrm{Na}$ atmosfera cálida da casa simples, aquecida pelo fogão de lenha no qual cozinha a comida dos Marujeiros, fala sobre as graças recebidas de Nossa Senhora do Rosário com alegria e devoção - mas sem exageros: "O que eu quero mais? Se eu pedir muito, ela fica com raiva de mim" (p.72). Tradições seculares mantidas por sutilíssimas ações: "Já estou esperando a festa deste ano! E vou ajudar com muito café!” (p.73).

Tata Fernandes é artista, filha, neta, tia, amiga, namorada, vizinha, fonoaudióloga, divulgadora, leitora, ouvinte. E musa. Tata é todas. Ricardo Santhiago, de maneira impressionista, descreve a gracilidade que emana de Tata - a mulher encantadora 
seguida por uma multidão colorida de crianças, alunas da sua oficina de composição. Tata, mais que impressionista - lírica -, narra a partir das felicidades do dia-a-dia, das pequenas delícias: ouvir bolerões de Glenn Miller durante a faxina, fingir tocar violão na praia com as primas, assistir a séries policiais nas madrugadas da TV, cuidar das plantas em casa - do mais singelo brota uma potente paixão pela vida. Não é de espantar que a foto de abertura de sua entrevista seja um gregário entrelaçar de mãos, marca distintiva de uma existência sempre compartilhada.

Também artista, Joana D'Arc foi vedete do teatro rebolado. Entre álbuns de fotografias e jornais antigos, narrou sua história de vida a Maria Aparecida Blaz Vasques Amorim. A extrema pobreza na infância, o glamour dos palcos, a vida na Europa, suas relações com os presidentes Getúlio e JK. Depois de circular pelos salóes do poder no Brasil do século XX, Joana, na velhice, reflete sobre sua trajetória sem arrependimentos: "Sabe, costumo dizer que minha vida se divide em três atos: um miserável, paupérrimo, outro de total apogeu e agora, tenho o terceiro, tranquilo, sem recalques" (p.124).

Suzana Lopes Salgado Ribeiro entrevistou Dona Ana Ramos, dona-de-casa e assentada rural. Escolhendo os legumes, preparando a comida do dia $e$ falando quase sempre no diminutivo, ela conta sua história desde o nascimento no interior de São Paulo até a vida cooperativa do assentamento. O cotidiano perpassa sua fala: em detalhes, Dona Ana relata o trabalho na horta medicinal comunitária, o cuidado das crianças, o serviço da casa: "O meu dia aqui é bom. Acordo, arrumo o café, saio, bato um papo com os vizinhos" (p.140). O que há de mais extraordinário neste cotidiano (como estampado no título do texto) é justamente o que ele tem de ordinário, de mais trivial.

A presença $e$ a atuação feminina no futebol brasileiro são retratadas por Marcel Diego Tonini, autor da entrevista com a árbitra-assistente Aline Lambert. Atento à posição da mulher em um ambiente predominantemente masculino, Tonini oferece importante contribuição documental ao discutir relações de gênero 
no seio da cultura futebolística. As influências familiares, vindas do pai árbitro, e o desenrolar de sua carreira na profissão pontuam um relato marcado pela consciência da especificidade de ser mulher, e das implicações que daí derivam, neste campo.

Edna Pereira é soldado da Polícia Militar do Ceará. Por ter participado do movimento grevista de 1997, foi excluída da corporação, sendo reintegrada quase oito anos depois. Voltada ao estudo da repercussão nacional deste movimento, a pesquisadora Juniele Rabêlo de Almeida insere a história de vida numa trama complexa. Para Almeida,

Edna aponta em sua narrativa importantes questões para o estudo do repertório da ação coletiva dos policiais grevistas, destacando a dificuldade de se compatibilizar o princípio da igualdade e o direito de participação, com preceitos militarizantes de disciplina e hierarquia (p.175).

Marta Gouveia de Oliveira Rovai nos apresenta Sônia Miranda, mulher que, segundo ela, "foge ao estereótipo feminino de fragilidade" (p.193). De formação católica, Sônia frequentou as reuniões promovidas pela Juventude Operária Católica e ganhou consciência sobre o momento histórico que vivia: a ditadura militar brasileira após 1968. Seu marido, sindicalista-metalúrgico, foi levado para o DOPS, onde foi preso e torturado. Escondida no interior do Rio de Janeiro, viu-se só: "Estava sozinha com três crianças! Lavava e secava fralda com ferro. E só chovia!" (p.205). Apesar disso, os traumas e as lutas diárias moldaram a educação de seus filhos, "pessoas conscientes e comprometidas com a solidariedade, a ética, a justiça" (p.209).

Surda desde os 11 anos, em decorrência de uma meningite, Sônia Oliveira é a última entrevistada do livro. Fábio Bezerra de Brito introduz a entrevista enfatizando que Sônia viveu uma "experiência de inclusão extemporânea", numa escola regular, aprendendo a falar e a entender a palavra falada via leitura labial - adaptando-se a um mundo oralizado. Só depois de adulta, 
contudo, Sônia descobriu a Língua Brasileira de Sinais (Libras) e, a partir daí, passou a se reconhecer como surda ("Conheci um mundo diferente e fiquei dividida entre eles, o mundo surdo $e$ o mundo ouvinte, até dar um jeitinho de transformá-los num único, pelo menos na minha vivência" (p.231) e a construir uma outra inclusão.

A relação da história oral com a história das mulheres e os estudos de gênero é bastante conhecida, seja na produção nacional ou estrangeira, na forma de trabalhos teóricos ou temáticos. Narrativas e Experiências dialoga com essa tradição, mas possui uma qualidade singular. Além das histórias de vida, matéria primeira do livro, os textos dos entrevistadores exibem a dimensão metodológica de seus trabalhos individuais, como notas de um caderno de campo; oscilam entre etnografias impressionistas e relatos minuciosos sobre os caminhos de suas pesquisas. Contribuições consistentes tanto à prática da história oral (área de atuação dos autores) como à sua aplicação direta aos estudos de gênero.

Narrativas e Experiências é para ser lido a partir da capa. Fugindo a convencionalismos, ela reproduz uma folha de planta bem de perto, com suas cores e nervuras - dando a ver aproximações e afastamentos entre essas mulheres, suas narrativas e experiências, sempre em movimento. A brasilianista Daphne Patai, na quarta-capa, define a obra como "um mosaico rico de memórias e vivências". Longe da aleatoriedade de uma colcha de retalhos, um mosaico tem caráter dual: a individualidade das tésseras, visto de perto; e o coletivo da forma, visto de longe. Igualmente, o leitor deve mover-se entre o que cada uma destas mulheres tem de particular e o quadro que juntas compõem: modos de viver o feminino no Brasil contemporâneo. 